\title{
Intracranial abscess as a complication of nasal septal abscess
}

\section{Leigh J. Sowerby MD, Erin D. Wright MDCM MEd}

Competing interests: None declared by Leigh Sowerby. Erin Wright has received funds from Johnson \& Johnson Medical

Companies and Merck, and travel expenses from

Medtronic

This article has been peer reviewed.

\section{Affiliation: From the}

Division of Otolaryngology

- Head and Neck Surgery,

University of Alberta,

Edmonton, Alta.

Leigh Sowerby,

lsowerby@uwo.ca

CMAJ 2013. DOI:10.1503 /cmaj.120431

\section{Correspondence to:}

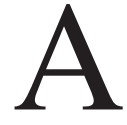
22-year-old man presented to the emergency department with nasal trauma after being involved in a violent altercation. There was no abnormality or fracture seen on physical examination and radiography, and he was sent home. He was subsequently assessed by a physician on posttrauma days 5 and 6 for facial pain and nasal obstruction with purulent discharge. He was prescribed cefuroxime for a diagnosis of sinusitis. On posttrauma day 7 , he was brought by ambulance to the emergency department after experiencing new-onset tonic-clonic seizures, along with a severe headache and blurred vision. Physical examination showed bilateral boggy swelling of the nasal septum (Appendix 1, video available at www.cmaj.ca /lookup/suppl/doi:10.1503/cmaj.120431/-/DC1). Anterior rhinoscopy and magnetic resonance imaging (MRI) showed a large nasal septal abscess, with intracranial abscess seen on MRI (Figure 1; Appendix 2, available at www.cmaj.ca

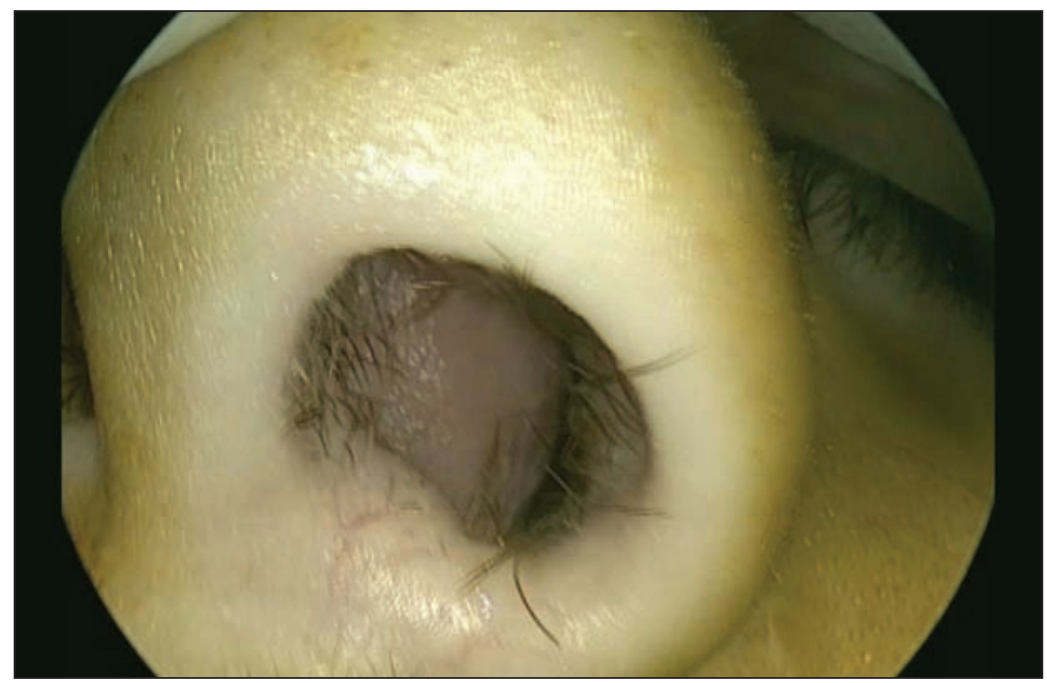

Figure 1: Anterior rhinoscopy showing an easily visualized nasal septal abscess in a 22-year-old man.

See the following video online:

Appendix 1: Examination of a nasal septal abscess.

www.cmaj.ca/lookup/suppl/doi:10.1503/cmaj.120431/-/DC1.
/lookup/suppl/doi:10.1503/cmaj.120431/-/DC1). An emergent craniotomy for drainage of the epidural abscess was performed with concurrent drainage of the septal abscess and nasal packing. The patient had complete neurologic recovery, but saddle nose subsequently developed secondary to loss of septal cartilage.

Nasal septal abscess is an uncommon sequel of nasal trauma and septal hematoma. Estimates based on retrospective chart reviews place the incidence of septal hematoma at $0.9 \%$ of people treated for nasal trauma, although most reports are based on pediatric populations and may not reflect the incidence in adult nasal trauma. ${ }^{1-4}$ The progression of a hematoma to purulence can start within 3 days and can lead to an abscess in 5 to 7 days. ${ }^{1}$ An abscess can cause septal cartilage resorption, septal perforation, saddle nose and intracranial complications. Intracranial involvement is exceedingly rare but illustrates the potentially life-threatening consequences of a missed diagnosis. ${ }^{1}$ A delay of days in diagnosis has been shown to lead to more severe and life-threatening complications such as cavernous sinus thrombosis and meningitis. ${ }^{2}$

Any patient presenting with acute nasal obstruction and a history of facial or nasal trauma should raise the index of suspicion for a septal hematoma. Early rhinoscopy with an otoscope can easily determine the presence of septal hematoma, with further confirmation by palpation and simple aspiration. Early detection and drainage of the septal hematoma is the most important step in the prevention of abscess development.

\section{References}

1. Thomson CJR, Berkowitz RG. Extradural frontal abscess complicating nasal septal abscess in a child. Int J Pediatr Otorhinolaryngol 1998;45:183-6.

2. Alshaikh N, Lo S. Nasal septal abscess in children: from diagnosis to management and prevention. Int J Pediatr Otorhinolaryngol 2011;75:737-44.

3. Holt GR. The immediate open reduction of nasal septal injuries. Ear Nose Throat J 1978;57:343-54.

4. Zielnik-Jurkiewicz B, Olszewska-Sosinska O, Rapiejko P. Treatment of nasal septal hematoma and abscess in children. [article in Polish]. Otolaryngol Pol 2008;62:71-5.

Acknowledgement: The authors thank Cale Moore for his assistance in the preparation of this article. 